\title{
Gene network-based analysis identifies two potential subtypes of small intestinal neuroendocrine tumors
}

\author{
Mark Kidd ${ }^{1 *}$, Irvin M Modlin ${ }^{1 *}$ and Ignat Drozdov²
}

\begin{abstract}
Background: Tumor transcriptomes contain information of critical value to understanding the different capacities of a cell at both a physiological and pathological level. In terms of clinical relevance, they provide information regarding the cellular "toolbox" e.g., pathways associated with malignancy and metastasis or drug dependency. Exploration of this resource can therefore be leveraged as a translational tool to better manage and assess neoplastic behavior. The availability of public genome-wide expression datasets, provide an opportunity to reassess neuroendocrine tumors at a more fundamental level. We hypothesized that stringent analysis of expression profiles as well as regulatory networks of the neoplastic cell would provide novel information that facilitates further delineation of the genomic basis of small intestinal neuroendocrine tumors.

Results: We re-analyzed two publically available small intestinal tumor transcriptomes using stringent quality control parameters and network-based approaches and validated expression of core secretory regulatory elements e.g., CPE, PCSK1, secretogranins, including genes involved in depolarization e.g., SCN3A, as well as transcription factors associated with neurodevelopment (NKX2-2, NeuroD1, INSM1) and glucose homeostasis (APLP1). The candidate metastasis-associated transcription factor, ST18, was highly expressed ( $>14$-fold, $p<0.004)$. Genes previously associated with neoplasia, CEBPA and SDHD, were decreased in expression $(-1.5--2, p<0.02)$. Genomic interrogation indicated that intestinal tumors may consist of two different subtypes, serotonin-producing neoplasms and serotonin/substance P/tachykinin lesions. QPCR validation in an independent dataset $(n=13$ neuroendocrine tumors), confirmed up-regulated expression of $87 \%$ of genes (13/15).

Conclusions: An integrated cellular transcriptomic analysis of small intestinal neuroendocrine tumors identified that they are regulated at a developmental level, have key activation of hypoxic pathways (a known regulator of malignant stem cell phenotypes) as well as activation of genes involved in apoptosis and proliferation. Further refinement of these analyses by RNAseq studies of large-scale databases will enable definition of individual master regulators and facilitate the development of novel tissue and blood-based tools to better understand diagnose and treat tumors.
\end{abstract}

Keywords: Blood, Gene marker, Microarray, Network, Neurodevelopment, Neuroendocrine tumor, aPCR, Secretome, Transcript

\footnotetext{
* Correspondence: mark.kidd@yale.edu; imodlin@optonline.net

${ }^{1}$ Yale University School of Medicine, New Haven, CT 06510, USA

Full list of author information is available at the end of the article
} 


\section{Background}

Neuroendocrine neoplasms (NENs) or NETs represent 1$2 \%$ of all neoplasia and are comparable in incidence to testicular cancer, gliomas and Hodgkin's lymphoma [1]. The most common variety, constituting approximately $29 \%$ of all NETs, develops within the small intestine or "midgut" and are the most common tumor of the small intestine $[2,3]$. Although previously considered to be benign, they are indolent cancers ( $60 \%$ overall five year survival rate) exhibiting a better survivals than adenocarcinomas of the same location $[2,4]$. Although their biological behavior is generally non-aggressive, metastatic invasion is evident in

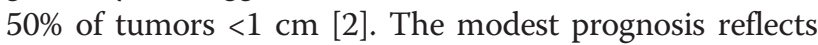
the inherent clinical difficulty in diagnosis of small intestinal malignancy; disease may often have been present for some time before identification [2].

NETs are considered to be derived from neuroendocrine cells within the diffuse neuroendocrine system [5]. Like normal neuroendocrine cells, tumors exhibit a functional secretory apparatus e.g., chromogranins and proteins involved in amine uptake e.g., VMATs, as well as vesicular trafficking and fusions e.g., SNAP25 [6-9]. In addition, well-described signaling pathways involving G-protein coupled receptors such as somatostatin and dopamine have been defined e.g., cAMP/PKA [10,11]. These have provided the basis for establishment of a histological classification, the development of targeted agents e.g., peptide receptor radiotherapy, as well as imaging strategies that utilize identification of cellular amine uptake mechanisms $[12,13]$. The transcriptomic basis of tumor development and malignancy, however, remains largely unknown.

Chromosomal-based studies $[14,15]$ e.g., CGH and high resolution SNP arrays [16] and molecular profiling through exome analyses have identified alterations e.g., loss of 18q22-mer [17,18] or SMAD4 LOH [19], that may be associated with neuroendocrine neoplasia. Similarly, gene expression profiling has identified a plethora of "marker genes" that include NAP1L1 [20], NKX2-3 [21], TGFßR2 [22] and CD302 [23]. However, no studies have been undertaken to generate an integrated molecular view of these neoplasms - the "interactome". The relevance of such an analysis is that the delineation of the transcriptome, as a global measure, offers a complete overview of the cellular machinery at an RNA level - the cellular "toolbox". This information provides the basis whereby network analysis can be utilized to identify specific interactive pathways associated with e.g., proliferation and metastasis rather than individual components. The establishment of the integrative pathways regulating the biological functions that constitute malignancy will likely have substantial translational applications.

Transcriptomic analysis can thus be utilized to provide a better understanding of tumor development as well as neoplasia. Such analyses have been demonstrated to be of considerable utility in other tumor types e.g., breast, particularly when translated to the clinical setting. Thus, considerable advance has occurred by upgrading histopathology, where gene-based analyses have allowed for the development of PCR-based arrays as well as custom-built chips to assess breast cancer classification [24-26], metastases [27] as well as predict therapeutic responsiveness [28]. Circulating tumor cells can readily be detected through PCR applications - such approaches appear to be more sensitive than current capture-based techniques and may be more informative especially because multiple, biologically informative genes identified from RNA analyses can be assessed e.g., in non-small cell lung cancer [29], prostate cancer [30] or colon cancer [31]. Finally, a logical framework for the development of therapeutic targets can be generated through in silico-based reverse engineering of transcriptome data - this has previously been used to identify signaling pathways e.g., CREB targets [10] as well as master regulators - cardinal, potentially targetable genes that regulate nodes in pathways [32,33].

Given the absence of any large-scale transcriptome study and the lack of analytical homogeneity between different NET transcriptome studies, we reanalyzed two publically available small intestinal NET microarray datasets [20,21] (ArrayExpress: E-GEOD-6272/E-TABM$389)$. In order to identify genes that constitute the intestinal "NETwork", we used a strategy that included stringent quality control techniques consistent with differential expression and validated network-based approaches [10,34-36]. Thereafter, we undertook qPCR to corroborate transcript alterations in candidate targets in an independent collection of NETs. Finally, we screened public databases (e.g., [37]) and published literature (e.g., [38]) to focus on validated signaling pathways and critical transcription factors. This approach allowed us to confirm or reconsider known disruptions in signaling pathways in small intestinal NETs and identify pathways involved in development as well as novel transcription targets with putative therapeutic and biomarker potential.

\section{Results}

\section{Sample set 1}

Of the 22,283 features, 10,763 were present in more than $50 \%$ of total samples $(n=6)$ and therefore retained for further analysis. Overall, 7519 genes and 12 samples passed quality control procedures (see Additional file 1: Supplementary Methods, Additional file 2: Figure S1, Additional file 3: Figure S2 and Additional file 4: Figure S3) and were retained (Figure 1A, B). Of these, 781 up-regulated and 368 down-regulated genes were identified. The most differentially expressed genes are included in Table 1 and Figure 1C. Highly expressed genes included SCG5 (Fold change $[\mathrm{FC}]+33.4, p=0.03)$, PCSK1 and PCSK1N (FC + 30.6-28.6, $p<0.05), \quad$ SCN3A $\quad(\mathrm{FC}+19.2, \quad p<0.02)$, 

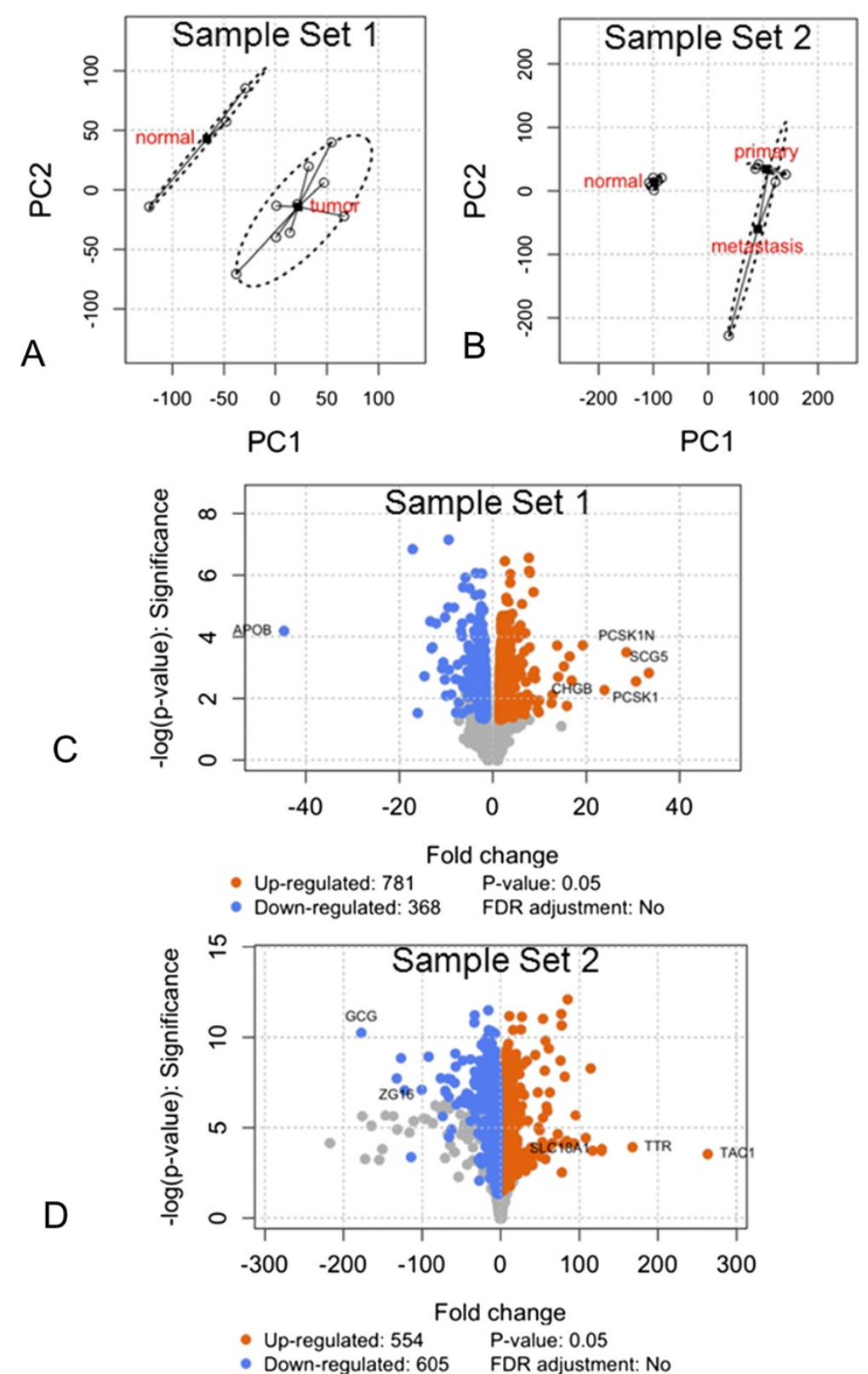

Figure 1 Re-analysis of two small intestinal NET sets (details in methodology). A, B. Principal component analysis and scatterplot of arrays along the first two principal components demonstrating spatial separation between control (normal mucosa) and tumor samples. C, D. Volcano plot of differentially expressed genes in Tumor compared to Normal for each of the sample sets. The most differentially expressed genes are labeled according to their fold changes.

PNMA2 $(\mathrm{FC}+16.3, p<0.02)$ and NKX2-2 $(\mathrm{FC}+15.2$, $p<0.03)$. Additionally, differential expression analysis identified transcription factors such as INSM1 and NKX2-2, regulatory nucleoproteins including BEX1, PNMA2, AKT3, and CEBPA, transcripts involved in regulation of secretion through depolarization (e.g., SCN3A) and the regulation of insulin signaling and homeostasis (e.g., APLP1). Secretory protein subnetwork analysis identified members of the secretogranin family (e.g., SCG2, SCG3, SCG5) and involvement of the serotonin metabolic pathway (TPH1, ATP7A) (Figure 2A). Assessment of microarray expression of the 29 enteroendocrine transcription factors (TFs) previously identified in highly enriched gut endocrine cells [38], demonstrated the expression of four TFs including INSM1, NKX2-2 and ST18 (Figure 3A). Comparison of gene expression in Set 1 with the Sanger COSMIC dataset [37] identified five down-regulated genes that have previously been confirmed to result in neoplasia [39-43]; these included CEBPA, ERBB2, EXT1, PIM1, and SDHD. Differentially 
Table 1 Highly elevated genes in each of the two sample sets based on microarray re-analysis

\begin{tabular}{llllll}
\hline Sample 1 [20] & & & Sample 2 [21] & \\
\hline Symbol & Fold change & Adjusted P-value & Symbol & Fold change & Adjusted P-value \\
SCG5 & +33.4 & $3.9 \mathrm{E}-02$ & TAC1 & +263 & $1.6 \mathrm{E}-03$ \\
PCSK1 & +30.7 & $5.2 \mathrm{E}-02$ & TTR & +167 & $8.5 \mathrm{E}-04$ \\
PCSK1N & +28.6 & $2 \mathrm{E}-02$ & PCSK2 & +128 & $1.2 \mathrm{E}-03$ \\
SCN3A & +19.2 & $1.6 \mathrm{E}-02$ & GPM6A & +116 & $1.87 \mathrm{E}-06$ \\
PNMA2 & +16.4 & $2.4 \mathrm{E}-02$ & & & \\
NKX2-2 & +15.2 & $3.2 \mathrm{E}-02$ & & & \\
\hline
\end{tabular}

expressed genes and all functional enrichments are listed in Additional file 5: Table S1.

\section{Sample set 2}

Of the 54,675 features, 12,420 genes passed quality control procedures and were retained. Differential expression analysis identified 554 up-regulated and 605 downregulated genes. The most differentially expressed genes are shown in Table 1 and Figure 1D. Highly expressed genes included TAC1 (substance P/tachykinins: FC+ 263, $\left.p<10^{-3}\right)$, TTR $\left(\mathrm{FC}+167, p<10^{-4}\right)$ and PCSK2 $\left(\mathrm{FC}+128, \quad p<10^{-3}\right)$. Secretory protein subnetwork

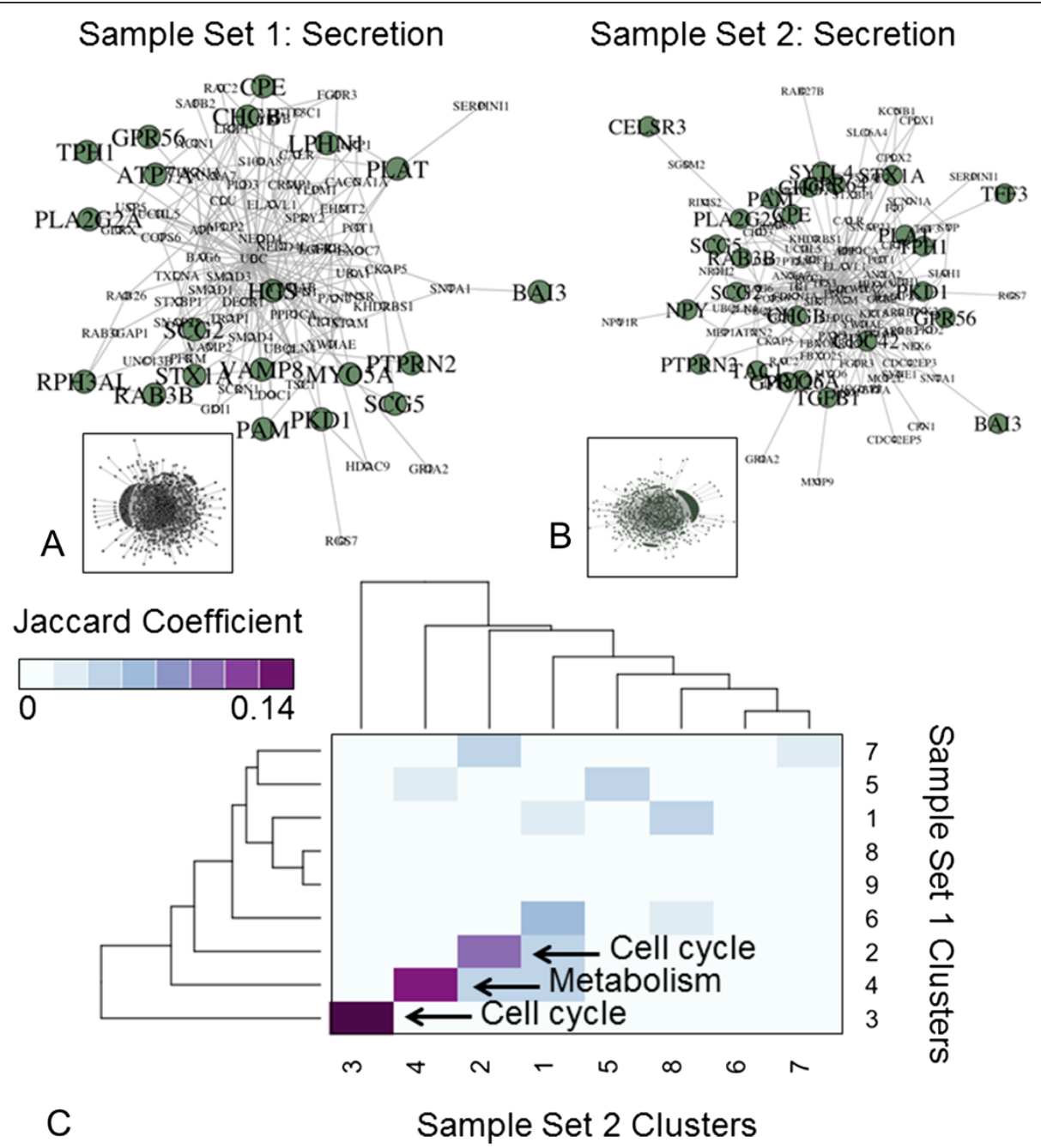

Figure 2 Secretory interactome analysis of two small intestinal NET sets. A, B. BioGRID secretory protein-protein interaction subnetworks of small intestinal NET microarrays. Proteins involved in secretory function are shown in green, while their neighbors are shown in white. Key genes in these pathways were examined by qPCR in the independent set (see Figures 3 and 4). C. Subnetwork cluster similarity heatmap. Darker shades reflect greater extent of shared proteins across network clusters in the two small intestinal NET protein-protein interaction subnetworks. 
Sample Set 1

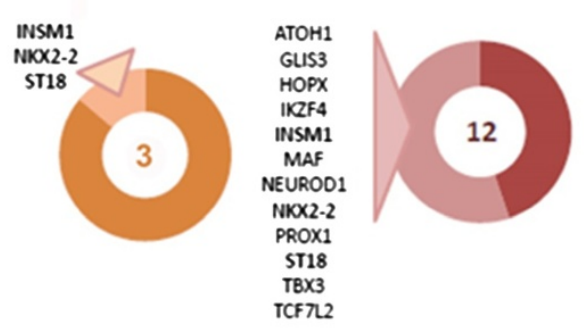

A

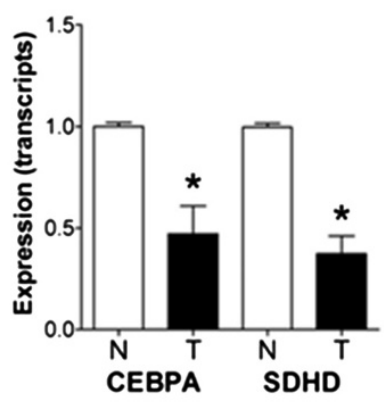

B

Figure 3 Neurodevelopmental and COSMIC-based transcript expression in SI NET samples. A. Enteroendocrine-related transcription factors in each of the data sets identified expression of 3 and 12 murine ortholog TFs, respectively. Commonly expressed TFs, involved in the regulation of neurodevelopment, included INSM1, NKX2-2 and ST18. B. QPCR analysis of transcripts predicted by COSMIC analysis to be decreased in small intestinal NETs. Both CEBPA and SDHD expressed levels $~ 50 \%$ of normal mucosa consistent with a decreased expression and potentially a loss of function as has been noted in hematological cancers [71] and paragangliomas [39]. C. QPCR analysis of neurodevelopmental transcripts in the independent set confirmed elevated expression of INSM1, and NEUROD1 and elevated expression of BEX1 and NKX2-2 validating the

transcriptome-based analyses. Mean \pm SEM, ${ }^{*} p<0.05$ vs. normal mucosa. Tumors $n=13$, normal mucosa $n=8$.

analysis identified a core set associated with secretion e. g., SCG2, SCG3, SCG5, SCN3A, serotonin metabolism (TPH1), and tachykinin receptor signaling (TAC1) (Figure 2B). Assessment of candidate enteroendocrine TFs identified expression of 12 TFs including INSM1, NEUROD1, NKX2-2, ST18 and TBX3 (Figure 3A). Comparison of gene expression in Set 2 with the Sanger COSMIC dataset identified twenty-nine down regulated genes previously confirmed to result in neoplasia; these included BCL11B, BUB1B, CANT1, CEBPA, EZR, FGFR2, HMGA1, HMGA2, LCK, MAF, MALT1, MYCL, POU2AF1, PPARG, PRDM1, and TNFRSF17. Differentially expressed genes and all functional enrichments are listed in Additional file 6: Table S2.

\section{Co-analysis of NET microarrays}

At the protein-protein interaction level, interactions involved in "Cell cycle" and "Metabolism" were the most conserved between the two datasets (Figure 2C). Additionally, a correlation was noted between changes in common gene expressions for Set 1 and Set 2 datasets $\left(n=7,299, \mathrm{R}=0.50, \mathrm{p}=2.2 \times 10^{-16}\right.$, Figure $\left.4 \mathrm{~A}\right)$. Interestingly, there were only 306 shared differentially expressed genes (26\% of Set 1 and Set 2 ) between the two sample sets (Table 2). These included the SCG and PCSK family of genes, SCN3A, PNMA2, and the transcription factors, NKX2-2, ST18 and INSM1 (Figure 4B, C). At a Gene Ontology Biological Process level, the two tumor sets expressed overlapping enrichments in terms including "Secretion", "Xenobiotic metabolic process", and "Neuron development" (20\% overlap) (Figure 4D). Similarly, overlapping Gene Ontology Cellular Component terms included "Secretory Granule" and "Vesicle Membrane" (22\% overlap), while overlapping Molecular Process terms included "Voltage-gated Cation Channel Activity" and "Phospholipase Activity" (12\% overlap) (Figure 4D). Reactome pathway analysis identified $73 \%$ overlap across significantly enriched pathways in Set $1(n=192)$ and Set $2(n=182)$; these included "Cell Cycle" and "Platelet Homeostasis (Figure 4D).

\section{PCR validation in independent set}

qPCR analysis confirmed up regulated expression of 13/15 (87\%) genes in small intestinal NETs compared to normal 


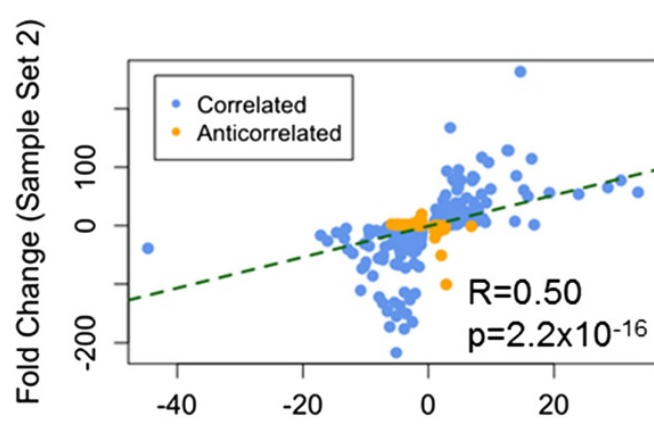

A Fold Change (Sample Set 1)
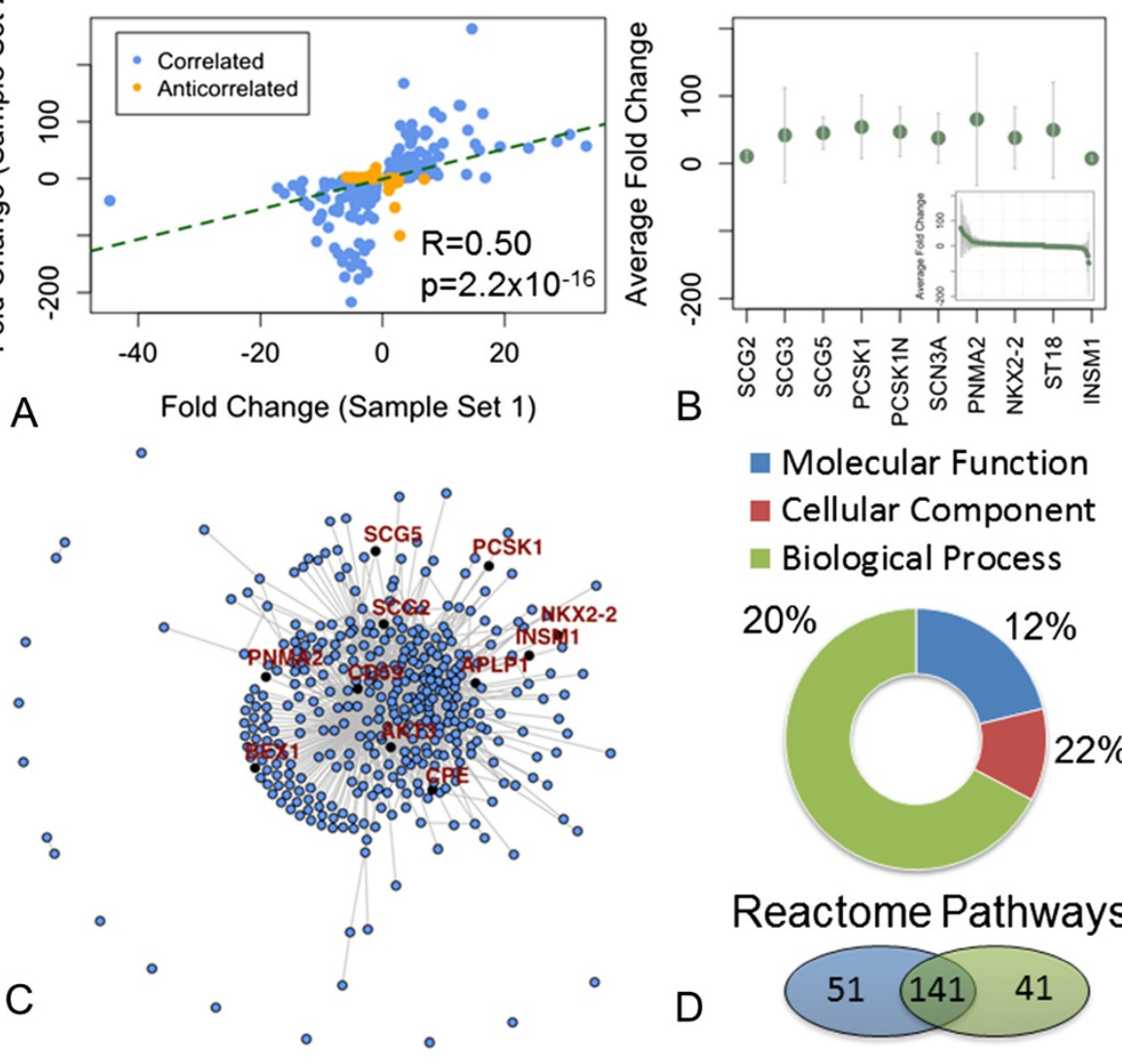

Molecular Function

- Cellular Component Biological Process

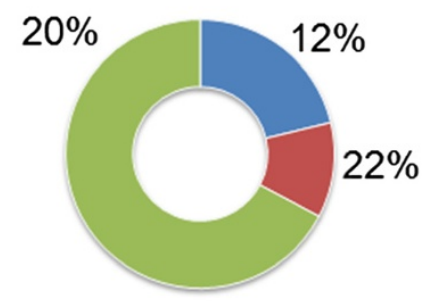

Reactome Pathways

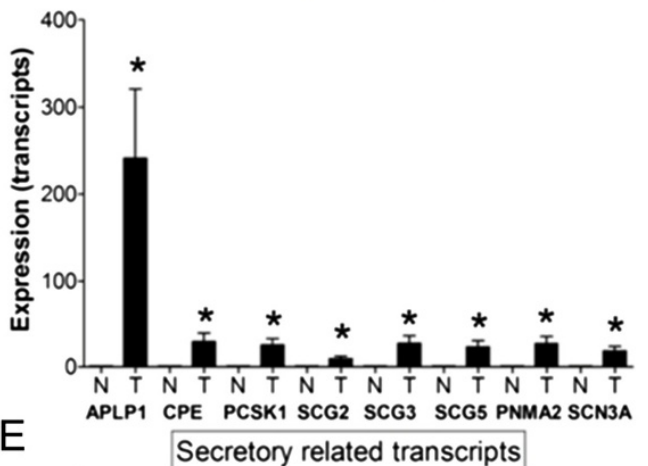

D
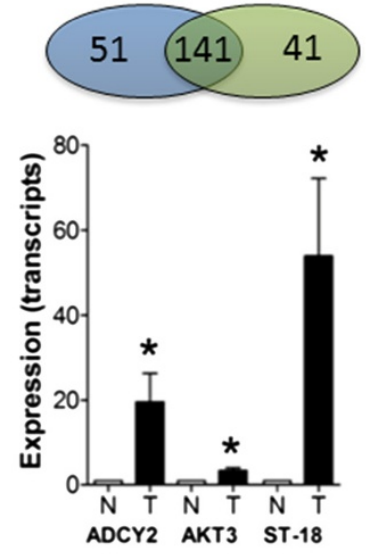

Figure 4 Co-analyses of the two small intestinal NET sets. A. Correlation profile of transcript alterations in each of the tumor sets. Both tissue databases were marginally correlated $(R=0.50)$. B. Commonly elevated transcripts in both datasets predominantly include genes involved in neuroendocrine secretion and regulation thereof. Error bars indicate the range of fold changes across the two datasets, while green points reflect average gene expression. C. Network analysis of the top ranked genes (see B) identified the most densely connected module to be related to secretion (interactome identified by multiple links). D. Gene-ontology and Reactome pathway demonstrating overlap between the two tumor sets; common pathways included secretion and xenobiotic responses (toxic environmental chemicals) as well as neurodevelopmental gene expression and alternative metabolic cycling (urea and TCA) consistent with a hypoxic phenotype (see Additional file 5: Table S1 and Additional file 6: Table S2). E. QPCR analysis of secretome-related transcripts in the independent set identified significant over-expression of all eight genes (ranging from APLP1 to SCN3A). * $p<0.05$ vs. normal mucosa. 3F. QPCR analysis of highly expressed transcripts in the independent set identified significant over-expression of $A D C Y 2$, AKT3 and ST18. Mean \pm SEM, ${ }^{*} p<0.05$ vs. normal mucosa. Tumors $n=13$, normal mucosa $n=8$.

mucosa. Of the most expressed genes (identified at a transcriptome level), SCG5 (FC $+24, p<0.04)$, PCSK1 $(\mathrm{FC}+26, p<0.02)$, SCN3A $(\mathrm{FC}+19, p<0.002)$, PNMA2 $(\mathrm{FC}+27, p<0.05), \mathrm{NKX} 2-2(\mathrm{FC}+23, p<0.002), \mathrm{BEX} 1$ $(\mathrm{FC}+100, p<0.002)$ and APLP1 $(\mathrm{FC}+240, p=0.01)$ were all highly expressed as was the transcription factor ST18 $(\mathrm{FC}+43, p<0.003)$ (Figure 4E-F). Transcripts associated with the COSMIC database and predicted to be downregulated included SDHD (FC-2.5, $p<0.002)$ and CEBPA $(\mathrm{FC}-2, \quad p<0.02) \quad$ (Figure $3 \mathrm{~B})$. Core regulatory genes 
Table 2 Commonly over-expressed genes in both datasets

\begin{tabular}{lll}
\hline Concurrent analysis* & \\
\hline Symbol & Name & Process/function \\
\hline SCG5 & Secretogranin V (7B2 protein) & Transport/Enzyme inhibitor activity \\
PCSK1 & Proprotein convertase subtilisin/kexin type 1 & Energy reserve metabolic process/Endopeptidase activity \\
SCN3A & Sodium channel, voltage-gated, type III, alpha subunit & lon transport/Noltage-gated ion channel activity \\
PNMA2 & Paraneoplastic Ma antigen 2 & Apoptotic process/Protein binding \\
NKX2- & NK2 homeobox 2 & Type B pancreatic cell development/Core promoter proximal region DNA \\
$\mathbf{2}$ & & binding \\
SCG2 & Secretogranin II & MAPK cascade/Cytokine activity \\
ST18 & Suppression of tumorigenicity 18 (breast carcinoma) & Negative regulation of transcription from RNA polymerase II promoter/DNA \\
& (zinc finger protein) & binding \\
INSM1 & Insulinoma-associated 1 & Regulation of transcription, DNA-dependent/DNA binding \\
CPE & Carboxypeptidase E & Cardiac left ventricle morphogenesis/Carboxypeptidase activity \\
BEX1 & Brain expressed, X-linked 1 & Multicellular organismal development/RNA polymerase II activating \\
& & transcription factor binding \\
APLP1 & Amyloid beta (A4) precursor-like protein 1 & MRNA polyadenylation/Protein binding \\
AKT3 & V-akt murine thymoma viral oncogene homolog 3 (protein & Mitochondrial genome maintenance/Nucleotide binding \\
& kinase B, gamma) & \\
CD59 & CD59 molecule, complement regulatory protein & Cell surface receptor signaling pathway/Protein binding \\
\hline
\end{tabular}

*This manuscript.

involved in neurodevelopment were also expressed (FC + 3-6) (Figure 3C).

\section{Discussion}

The precise basis of small intestinal tumor genomic profile has proven to be a complex subject and an integrated, cellular transcriptomic appreciation of neuroendocrine tumors has heretofore not been possible. This reflects a number of issues namely the paucity of studies available, the low number of tumor samples analyzed, the divergent analytical tools utilized and dissimilar focuses of the investigative groups e.g., focus on identifying metastatic genes [20]. We sought to define the issue using an integrated transcriptome analysis based on gene network-approaches that has successfully been proven to identify associations not previously apparent [10,34-36]. Additionally, while it is likely that the current paradigm in tumor sequencing calls for tumor samples to be matched with control samples from the same individual [44], we hypothesized that comparing diverse population may shed light on tumorspecific behavior rather than on sample-specific behavior. Overall, the information derived (from two independent datasets) demonstrates four areas of novelty and considerable interest. Firstly, expression of core regulatory secretory regulatory elements, including genes involved in depolarization, was identified. The data therefore provide a complete overview of genes involved in regulated secretion and demonstrate the conservation of secretory apparatus in these tumors. Secondly, a set of transcription factors associated with neurodevelopmental processes including INSM1, NKX2-2 and BEX1 were identified indicating that the regulation of neuroendocrine differentiation occurs in tumors and that aberrations of this process may be of biological relevance in the evolution of the neoplastic phenotype. Thirdly, we confirmed loss of $S D H D$ expression, a phenomenon associated with "benign" conditions in other tumors e.g., paragangliomas [39]. Finally, our data may suggest that at a genomic level small intestinal NETs may be distinguished by at least two distinct, secretory subtypes, serotonin-producing neoplasms and serotonin/substance $\mathrm{P}$ (TAC1/tachykinin)-producing lesions. As such, this is supported by previous studies in small intestinal NETs with "carcinoid syndrome" i.e., produce excess serotonin which suggests at least two subtypes of tumors. These include: 1) the demonstration that elevated luminal concentrations of substance $\mathrm{P}$ (secreted from mucosal sources) are only measured in $12 \%$ of patients [45]; 2) fasting circulating substance $P$ concentrations are elevated in $<20 \%$ of carcinoids [46]; and 3) at least two distinct serotonin producing NET lesions have been identified - serotonin producing NETs in the pancreas are TAC1/substance P negative [47].

\section{Serotonin-secreting tumors (Set 1)}

Genome-wide co-expression analysis of these lesions [20] revealed processes including 'Nervous system development' (e.g., BEX1, SYN1, GRIA2), 'Immune response' (e.g., CD38, IGKC, SLAMF8), and 'Cell-cycle' (e.g., ASPM, MKI67, TOP2A). Importantly, gene network topology and differential expression analysis identified over-expression of the GPCR signaling regulators, cAMP synthetase $(A D C Y 2)$, and the protein kinase A, PRKAR1A. 
$A D C Y 2$ was confirmed to be elevated in expression in our independent set; PRKAR1A and the role of cAMPsignaling have been previously studied in detail [10].

\section{Serotonin/substance P (TAC1)-secreting tumors (Set 2)}

A reanalysis of the microarray data [21] identified overexpression of common genes with Set 1 including APLP1, SCN3A, BEX, INSM1 and ST18. However, the most highly and uniquely expressed gene was $T A C 1$, or substance P/tachykinins. Our secretory subnetwork analysis suggests that these tumors may not be classical serotonin-producing lesions.

\section{Combinatorial-analysis}

This interactome assessment of the highly expressed genes identified canonical elements of secretory regulation including secretogranins, vesicle trafficking and hormone processing. The chromogranins $(\mathrm{CgA}$ and $\mathrm{CgB})$, secretogranins (secretogranin II and secretogranin III), and additional related proteins e.g., PCSK1 and 2 (which are found within dense core secretory granules in endocrine and neuroendocrine cells and process several hormones and neuropeptide precursors), PNMA2 (a secreted protein that may generate autoantibodies [48]), APLP1 (which colocalizes with APLP2 and synaptophysin [49]), as well as carboxypeptidase E (CPE) have essential roles in the regulated secretory pathway or as products of this pathway [50]. Elevated expression of these genes was confirmed by qPCR in an independent set and provides evidence corroborating the secretome fingerprint of the tumor cells. Of interest was the identification of high expression of SCN3A (Nav1.3). This tetrodotoxin-sensitive voltage-gated sodium channel gene mediates membrane depolarization in excitable cells [51]. This suggests that this gene may be involved in regulating aspects of neuroendocrine secretion which mechanistically require a depolarization event. It is clinically well recognized that small intestinal tumors are sensitized to paroxysmal increased release of serotonin or substance $\mathrm{P} /$ tachykinins by secretagogues [52]. In this respect, Nav1.3 is increased in expression following nerve injury with the concomitant phenomenon of hyperalgesia in dorsal root ganglia [53]. We speculate that this elevated expression of Nav1.3 in neuroendocrine tumors may be related.

An assessment of the twenty-nine enteroendocrinerelated transcription factors [38] identified that ST18, INSM1 and NKX2-2 were commonly expressed in both tumor sets. ST18 (Myt3) is a candidate tumor suppressor in breast cancer; ectopic expression in MCF-7 breast cancer cells strongly inhibits colony formation in soft agar and the formation of tumors in a xenograft mouse model [54]; it is also known to function as an proapoptotic effector [55]. This gene, however, is involved in neuronal differentiation [56] as well as in normal pancreatic islet cell development [57]. Interactome analysis of small intestinal NET transcriptomes identified neuroendocrine developmental pathways to be a key feature of these lesions. INSM1, NKX2-2, and NEUROD1 were all identified to co-exist and elevated expression levels of these genes were confirmed by qPCR. Identification of other genes for example, TBX family members, in each transcriptome dataset supports a common activation of developmental pathways in these lesions and suggested the existence of a network of transactivating factors that function together to regulate the neuroendocrine phenotype. Further support for this is provided by overexpression of $B E X 1$ which is considered a regenerationassociated gene [58] and may be involved in tumorigenesis [59]. Bex1 is epigenetically activated in neurosphere cells and is considered relevant as a marker of reactivation of stem cell and pluripotency-associated genes; Bex1 expression enlarges the differentiation potential of precursor cells [60]. These data suggest that transcription factors that regulate neuroendocrine cell development or lineage specification are upregulated in neuroendocrine tumors as has been noted in lung tumors [61]. This may indicate an active control of the neuroendocrine phenotype in tumors but also raises the question as to whether an abnormal phenotype (i.e. less well-differentiated tumor) could occur as a consequence of a disruption in the TFs (e.g., through methylationmediated repression) that co-ordinate the neurodevelopmental pathway. A similar phenomenon has been identified for tumor progenitor cells in small cell lung cancer [62].

At a developmental level, INSM1, apart from regulating neural and olfactory development [63], is essential for proper specification of both gastrointestinal and pancreatic endocrine cells [64] through interruption of cell cycle signaling, and cellular proliferation inhibition [65]. Endocrine transdifferentiation in BON cells is mediated by INSM1 through activation of NGN3 [66]. The plasticity of the neuroendocrine phenotype is controlled by NKX2-2 which regulates cell fate choices within the intestinal enteroendocrine population [67]. When this transcription factor is down-regulated, pancreatic alphaand beta-cell development is impaired; the ghrelinexpressing cell population, in contrast, is augmented [68]. Upregulation of NKX2-2 is considered one of the primary regulatory events required for the maintenance of beta-cell identity [69]. Although the precise role of these genes in NETs is unclear, given the known roles in neuroendocrine development, it seems plausible that activation of neuroedevelopmental pathway (s) can be implicated in NET proliferation. INSM1, at least, functions through disruption of the cell cycle by targeting the CDK4/CyclinD1 complex. 
A second gene linked to this complex is CEBPA (CCAAT/enhancer binding protein alpha (C/EBPalpha). This is a basic/leucine zipper transcription factor that integrates transcription with proliferation to regulate the differentiation of tissues involved in energy balance. In the pituitary, C/EBPalpha functions to prolong the cell cycle in G1 and S in pituitary progenitor cells [70]. An assessment of the 487 genes in the COSMIC database verified to be associated in a dominant or recessive fashion with cancer identified that CEBPA was downregulated in both NET groups we studied. QPCR confirmed decreased expression of this gene $(\sim 50 \%$ of mucosal expression). Loss of function of this gene is associated with AML and MDS, largely through regulation of differentiation; this gene product inhibits CDK2/4 and the cyclin D1 pathway [71]. We postulate that a similar mechanism exists in small intestinal NETs; elevations in cdks and cyclin expression are well-recognized in NETs particularly as a consequence of IGF-1 stimulation [72]. It is noteworthy that inhibition of proliferation using interferons specifically inhibits these effectors in vitro [73].

A consistent loss or decrease in expression of $S D H D$, a recessive gene involved in paragangliomas, was noted in both tumor sets. Mutations in SDHD result in loss of complex II function and are associated with loss of stabilization of HIF1 under normoxia and generation of reactive oxygen species [74]. Mutations in this gene are considered to result in a "benign" phenotype in paraganglioma, the mechanisms of which are considered to be due to activation of cellular hypoxia responses [39]. Although no mutations have been detected in SDHD in intestinal NETs [75], LOH has been identified in 30\% of lesions [76]. Interestingly, $\mathrm{LOH}$ alone could lead to a complete loss of function since SDHD is an imprinted gene [39]. QPCR, in an independent dataset, confirmed decreased expression ( $50 \%$ of normal mucosal levels) of $S D H D$ indicating a potential role for hypoxia in intestinal tumor biology.

\section{Conclusions}

We have identified two subtypes of intestinal neuroendocrine tumors, both associated with metastases, that express common signaling pathways involved in neuroendocrine secretion, nervous system and neuroendocrine development, as well as hypoxia and cyclin/CDK4 regulation. Transcriptome analyses have previously been leveraged to identify markers either of metastases [77] or blood-based antigens [48] or circulating transcripts [78]. The latter has evolved from a single transcript approach to a multiple gene screen - 51 marker genes - that are closely correlated with neuroendocrine tumor biology [79] and overlap with genes e.g., APLP1 family, PNMA2 and CD59, in the current study. Detection of this enhanced gene signature has been shown to be significantly more effective than measurements of chromogranin A by ELISA as a peripheral blood tool for detecting NETs [79]. In addition, because it is based on assessment of multiple NET transcriptomes it is also effective at identifying all gastroenteropancreatic lesions irrespective of the organ of origin and tumors including in the absence of metastasis.

This manuscript provides an integrated transcriptomic view of small intestinal neuroendocrine tumors and identifies that these lesions are regulated at a developmental level, have key activation of hypoxic pathways (a known regulator of malignant stem cell phenotypes) as well as activation of genes involved in apoptosis and proliferation. Further analyses and leverage of these data should provide novel tissue and blood-based tools to better understand, diagnose and ultimately treat these neoplasms.

\section{Methods}

Please refer to the Additional file 1: Supplementary Methods for detailed description of computational protocols.

\section{Gene expression arrays and independent validation set}

All samples were collected following informed consent and analyzed according to Ethics Committee requirements of Yale University (IRB: 0805003870; expires 6/ 18/2015) in accordance with the World Medical Association Declaration of Helsinki regarding ethical conduct of research involving human subjects [79]). Clinical details regarding the three samples sets are included in Table 3. No statistically significant differences were noted in distribution of gender, age or treatment received between each of the sets.

\section{Sample set 1}

Nine NET (obtained from the small intestine) transcriptomes and normal small intestinal mucosa (U133A chips, $n=9$ tumors and $n=3$ normal mucosa, ArrayExpress: E-GEOD-6272) [20]. Expression profiles were monitored across 22,283 probes.

\section{Sample set 2}

U133 Plus 2 chips, $n=6$ normal mucosa, $n=3$ primary midgut NETs, and $n=3$ GEP-NET metastases [METs] (ArrayExpress: E-TABM-389) [21].

\section{Sample set 3 (Independent validation set)}

Thirteen intestinal NETs (small intestine, including primary tumors: $n=8$, liver metastases: $n=5$ ) and eight normal small intestinal mucosa (matched samples) were collected. All samples were collected and analyzed according to a standard IRB protocol (Yale University: 6/5/ 2012) [79]. 
Table 3 Demographics of NETs (Sample sets 1-3)

\begin{tabular}{|c|c|c|c|c|c|c|}
\hline Sample set & Sample no. & Gender & Age range & Site & Metastases & Treatment $^{\#}$ \\
\hline 1 & $\mathrm{T1}$ & $M$ & $45-49$ & Ileum & $\mathrm{N}$ & $\mathrm{N}$ \\
\hline 1 & $\mathrm{~T} 2$ & $\mathrm{~F}$ & $60-64$ & lleum & $\mathrm{N}$ & $\mathrm{N}$ \\
\hline 1 & T3 & $F$ & $45-49$ & Ileum & $\mathrm{N}$ & $\mathrm{N}$ \\
\hline 1 & $\mathrm{~T} 4$ & M & $65-69$ & lleum & $\mathrm{N}$ & $\mathrm{N}$ \\
\hline 1 & T5 & $\mathrm{F}$ & $85-89$ & lleum & $\mathrm{N}$ & $\mathrm{N}$ \\
\hline 1 & T6 & M & $40-44$ & Ileum & $\mathrm{N}$ & $\mathrm{N}$ \\
\hline 1 & $\mathrm{T7}$ & $F$ & $65-69$ & Ileum & $\mathrm{N}$ & $\mathrm{N}$ \\
\hline 1 & T8 & M & $65-69$ & Ileum & $\mathrm{N}$ & $\mathrm{N}$ \\
\hline 1 & T9 & $\mathrm{F}$ & $55-59$ & Ileum & $\mathrm{N}$ & $\mathrm{N}$ \\
\hline 2 & $\mathrm{~T} 1$ & M & $70-74$ & Ileum & $\mathrm{N}$ & $\mathrm{N}$ \\
\hline 2 & $\mathrm{~T} 2$ & M & $80-84$ & Ileocecal junction & $\mathrm{N}$ & $\mathrm{N}$ \\
\hline 2 & T3 & $\mathrm{F}$ & $60-64$ & Ileum & $\mathrm{N}$ & $\mathrm{N}$ \\
\hline 2 & $\mathrm{~T} 4$ & M & $50-54$ & Liver* & Y & Y \\
\hline 2 & T5 & $\mathrm{F}$ & $60-64$ & Liver* & Y & Y \\
\hline 2 & T6 & $\mathrm{F}$ & $75-79$ & Liver* & Y & Y \\
\hline 3 & $\mathrm{~T} 1$ & $F$ & $65-69$ & Ileum & $\mathrm{N}$ & $\mathrm{N}$ \\
\hline 3 & $\mathrm{~T} 2$ & $\mathrm{~F}$ & $60-64$ & Ileum & Y & $\mathrm{N}$ \\
\hline 3 & T3 & M & $65-69$ & Ileum & Y & $Y$ \\
\hline 3 & T4 & $M$ & $65-69$ & Ileum & Y & $Y$ \\
\hline 3 & T5 & $\mathrm{F}$ & $60-64$ & Ileum & $N$ & $\mathrm{~N}$ \\
\hline 3 & T6 & $M$ & $75-79$ & Ileum & $\mathrm{N}$ & $\mathrm{N}$ \\
\hline 3 & $\mathrm{T7}$ & $\mathrm{F}$ & $60-64$ & Ileum & $\mathrm{N}$ & $N$ \\
\hline 3 & T8 & $F$ & $55-59$ & Ileum & $\mathrm{N}$ & $\mathrm{N}$ \\
\hline 3 & T9 & $M$ & $40-44$ & Ileum & Y & $\mathrm{N}$ \\
\hline 3 & T10 & $M$ & $45-49$ & Ileum & $\mathrm{N}$ & $N$ \\
\hline 3 & T11 & M & $50-54$ & Ileum & $\mathrm{N}$ & $\mathrm{N}$ \\
\hline 3 & $\mathrm{~T} 12$ & $\mathrm{~F}$ & $45-49$ & Ileum & $N$ & $\mathrm{~N}$ \\
\hline 3 & $\mathrm{~T} 13$ & $\mathrm{~F}$ & $50-54$ & Ileum & Y & $\mathrm{N}$ \\
\hline
\end{tabular}

"Treatment included somatostatin analogs and/or interferon [21].

*All patients had carcinoid syndrome [21] so presumably the primary tumors were derived from the small intestine.

Female $=$ female, $M=$ Male, $N=N o, Y=$ Yes.

\section{Gene expression analyses}

Individual analyses were performed using the web-based GeneProfiler tool (GeneProfiler, Bering Limited http://beringresearch.com/). Primary tumors were compared with non-matched normal mucosal samples. Sample set 1 consisted of 22,283 probes and 12 arrays, while sample set 2 consisted of 54,675 probes and 12 arrays. Probe sets that were unlikely to be reliable were eliminated using detection of Present/Absent calls. Probes present in more than $50 \%$ of samples were retained [80]. Raw probe intensities were normalized using the Robust Microarray Average (RMA) approach [81]. Array outlier detection was performed in the arrayQualityMetrics package [82] using the Kolmogorov-Smirnov statistic between each array's distribution and the distribution of the pooled data. To enhance microarray annotation, probe identifiers (IDs) were mapped to Entrez Gene IDs (accessed April 7, 2013) [83]. In cases were multiple probes mapped to the same Entrez ID, the average probe intensity was calculated. Probes without an Entrez record were removed from analysis. Genes that were consistently identified as differentially expressed using multiple ranking algorithms [84] (fold change ranking, ordinary $\mathrm{t}$-statistic, shrinkage $\mathrm{t}$-statistic, limma, significance analysis of microarrays) were called significant and retained for further analysis. This approach ensured that differential expression analysis was: 1) unbiased, and 2) consistent across different array platforms.

\section{Functional gene expression analysis}

Differentially expressed genes were enriched for Gene Ontology (GO) Biological Process (BP), Cellular Component $(\mathrm{CC})$, and Molecular Function (MF) terms using the top $G O$ 
Table 4 Details of Applied Biosystems Primers $(n=18)$, including the housekeeping gene, ALG9

\begin{tabular}{|c|c|c|c|c|c|c|}
\hline \multicolumn{2}{|c|}{ SI-NEN Biomarker or housekeeping gene } & \multirow[t]{2}{*}{ NCBI chromosome location } & \multirow[t]{2}{*}{ UniGene ID } & \multirow[t]{2}{*}{ RefSeq } & \multirow{2}{*}{$\begin{array}{l}\text { Amplicon produced using } \\
\text { forward and reverse primers } \\
\text { Length }\end{array}$} & \multirow[b]{2}{*}{ Exon boundary } \\
\hline Symbol & Name & & & & & \\
\hline ALG9* & $\begin{array}{l}\text { Asparagine-linked glycosylation 9, } \\
\text { alpha-1,2-mannosyltransferase homolog }\end{array}$ & Chr. 11-111652919- 111742305 & Hs.503850 & NM_024740.2 & 68 & $4-5$ \\
\hline ADCY2 & Adenylate cyclase 2 (brain) & Chr.5: $7396343-7830194$ & Hs.481545 & NM_020546.2 & 81 & $22-23$ \\
\hline AKT3 & v-akt murine thymoma viral oncogene homolog 3 & Chr.1: $243651535-244006886$ & Hs.498292 & NM_001206729.1 & 100 & $11-12$ \\
\hline APLP1 & Amyloid beta (A4) precursor-like protein 1 & Chr.19: $36359401-36370699$ & Hs.74565 & NM_001024807.1 & 142 & $11-12$ \\
\hline BEX1 & Brain expressed, $X$-linked 1 & Chr.X: $102317581-102319168$ & Hs.334370 & NM_018476.3 & 62 & $2-3$ \\
\hline CEBPA & CCAAT/enhancer binding protein (C/EBP), alpha & Chr.19: 33790840 - 33793430 & Hs.740432 & NM_004364.3 & 77 & $1-1$ \\
\hline CPE & carboxypeptidase E & Chr.4: 166300097 - 166419482 & Hs.75360 & NM_001873.2 & 106 & $7-8$ \\
\hline INSM1 & Insulinoma-associated 1 & Chr.20: 20348765 - 20351593 & Hs.89584 & NM_002196.2 & 72 & $1-1$ \\
\hline NEUROD1 & Neuronal differentiation 1 & Chr.2: $182541194-182545381$ & Hs.574626 & NM_002500.4 & 110 & $2-2$ \\
\hline NKX2-2 & NK2 homeobox 2 & Chr.20: 21491648 - 21494664 & Hs.516922 & NM_002509.3 & 114 & $1-2$ \\
\hline PCSK1 & Proprotein convertase subtilisin/kexin type 1 & Chr.5: $95726040-95768985$ & Hs.78977 & NM_000439.4 & 96 & $13-14$ \\
\hline PNMA2 & paraneoplastic Ma antigen 2 & Chr.8: $26362196-26371483$ & Hs.591838 & NM_007257.5 & 60 & $3-3$ \\
\hline SCG2 & Secretogranin ॥ & Chr.2: 224461658 - 224467121 & Hs.516726 & NM_003469.4 & 69 & $1-2$ \\
\hline SCG3 & Secretogranin III & Chr.15: 51973550 - 52013223 & Hs.232618 & NM_001165257.1 & 92 & $5-6$ \\
\hline SCG5 & Secretogranin V & Chr.15: 32933870 - 32989298 & s.156540 & NM_001144757.1 & 84 & $5-6$ \\
\hline SCN3A & Sodium channel, voltage-gated, type III, alpha subunit & Chr.2: $165944030-166060577$ & Hs.435274 & NM_001081676.1 & 71 & $12-13$ \\
\hline SDHD & $\begin{array}{l}\text { Succinate dehydrogenase complex, subunit } D \text {, } \\
\text { integral membrane protein }\end{array}$ & Chr.11: $111957571-111966518$ & Hs.356270 & NM_003002.2 & 187 & $4-4$ \\
\hline ST18 & $\begin{array}{l}\text { Suppression of tumorigenicity } 18 \text { (breast carcinoma) } \\
\text { (zinc finger protein) }\end{array}$ & Chr.8: $53023392-53322439$ & Hs.655499 & NM_014682.2 & 69 & $22-23$ \\
\hline
\end{tabular}

${ }^{*} A L G 9=$ housekeeping gene. 
Bioconductor package [85]. To ensure enrichment accuracy, terms with fewer than 10 assigned genes were not included in the analysis. Differentially expressed genes were also assessed at the Reactome pathway level (version 47) [86] using model-based gene set enrichment analysis [87].

For secondary analyses of selected genes, expression of genes relevant to carcinoma were assessed using the Sanger COSMIC database [37], while candidate enteroendocrine transcription factors were assessed against murine orthologs identified through transcriptome profiling of highly enriched populations [38]. The aim of these analyses was to assess the capacity to which differential expression analysis could identify previously known oncogenes and transcription factors.

\section{Protein-protein interaction network analysis}

Differentially expressed genes (seed nodes) were mapped to human interactions obtained from the BioGRID database (version 3.2.109, $n=15,068$ proteins and $n=$ 124,370 interactions) [88]. High-scoring differential subnetworks were extracted and visualized to identify putative signaling regulators (see Additional file 1: Supplementary Methods, Additional file 2: Figure S1, Additional file 3: Figure S2 and Additional file 4: Figure S3 for a full description of the methods). Briefly, for each differential expression analysis, network nodes were assigned a weight of $-\log _{10}(\mathrm{p}$-value). Subsequently, all shortest paths were calculated between seed nodes. Each shortest path was assigned a weight, expressed as the sum of nodes on that shortest path. A subnetwork was extracted by selecting seed nodes and "linker" nodes that fell on the highest weighted shortest path between the seed nodes.

Pairwise interaction network similarity was assessed by network community detection and subsequent calculation of inter-community similarity. For each network, protein communities were identified by optimizing the network modularity [89] (Additional file 1: Supplementary Methods, Additional file 2: Figure S1, Additional file 3: Figure S2 and Additional file 4: Figure S3). Similarity between protein communities was expressed using the Jaccard coefficient, computed as a ratio of the number of common proteins in any two network communities to the total number of proteins in these communities. Disparate and identical communities would correspond to Jaccard coefficient of 0 and 1 respectively.

Secretory protein subnetwork analyses were performed by extracting proteins from highly-scoring NET subnetworks involved in serotonin metabolism (GO:00 42428, GO:0042427, GO:0007210, GO:0004993), substance P signaling (GO:0071861, GO:0007217), and secretion (GO:0007218, GO:0030141).

\section{Real-time PCR validation (Independent Set)}

To validate candidate genes, we measured transcript expression in an independent Set 3 (SI NETs: $n=13$, normal mucosa: $n=8$ ) using real-time PCR. RNA was extracted (TRIZOL ${ }^{\bullet}$, Invitrogen, USA) [90,91] and real time RT-PCR analysis was performed using Assays-onDemand $^{\mathrm{Tm}}$ products and the ABI 7900 Sequence Detection System according to the manufacturer's suggestions $[90,91]$. Primer probe sets are included in Table 4. Cycling was performed under standard conditions (TaqMan Universal PCR Master Mix Protocol) and data normalized (using $A L G 9$ and the $\Delta \Delta C_{\mathrm{T}}$ method (Microsoft Excel). Non-parametric Mann-Whitney and Spearman correlations were used to compare samples and the Fisher's test was used for binary comparison (GraphPad Prism 5).

\section{Availability of supporting data section}

Small intestinal neuroendocrine tumor microarray datasets are available from ArrayExpress:

\section{Dataset 1}

E-GEOD-6272 (http://www.ebi.ac.uk/arrayexpress/experiments/E-GEOD-6272/).

\section{Dataset2}

E-TABM-389 (http://embl-ebi.org/arrayexpress/experiments/E-TABM-389/files/).

A supporting document with additional methodology information as well as 3 figures are included with this manuscript.

\section{Additional files}

Additional file 1: Supplementary Information [80-87,92].

Additional file 2: Figure S1. GeneProfiler pipeline for microarray processing and quality control, differential expression analysis, and functional enrichment.

Additional file 3: Figure S2. Overlap in the top 1000 differentially expressed genes between two datasets of the same tumor expressed as the Jaccard coefficient of similarity (number of genes in the intersection/ number of genes in the union)

Additional file 4: Figure S3. A toy graph to illustrate the implementation of our greatest-weighted shortest paths extraction algorithm. Seed nodes are shown in red, while linker nodes are shown in grey. The weight of each node is shown as a numerical label.

Additional file 5: Table S1. Differentially expressed genes and functional enrichment of Sample Set 1.

Additional file 6: Table S2. Differentially expressed genes and functional enrichment of Sample Set 2.

\section{Abbreviations}

CREB: CAMP Response Element Binding Protein; LOH: Loss of heterozygosity; NENs: Neuroendocrine neoplasms; NETs: Neuroendocrine tumors; QPCR: Quantitative PCR; SI: Small intestinal.

\section{Competing interests}

The authors declare that they have no competing interests. 


\section{Authors' contributions}

MK conceived and co-ordinated the study, participated in tissue collection, transcriptome analysis and real-time PCR, performed the statistical analysis, and drafted the manuscript. IMM conceived the study, and participated in its design, coordination and funding and helped to draft the manuscript. IAD performed the molecular studies, participated in the design of the study, performed statistical analyses and drafted the manuscript. All authors read and approved the final manuscript.

\section{Acknowledgements}

Funding for this project was provided by Clifton Life Sciences. This entity played no role in:

1) the design, collection, analysis, or interpretation of data;

2) in the writing of the manuscript; or

3) in the decision to submit the manuscript for publication.

**Presented at Digestive Disease Weekly, Orlando, Florida, May 20, 2013.

\section{Author details}

'Yale University School of Medicine, New Haven, CT 06510, USA. 'Bering Limited, Richmond, UK.

Received: 2 April 2014 Accepted: 7 July 2014

Published: 15 July 2014

\section{References}

1. Modlin IM, Oberg K, Chung DC, Jensen RT, de Herder WW, Thakker RV Caplin M, Delle Fave G, Kaltsas GA, Krenning EP, et al: Gastroenteropancreatic neuroendocrine tumours. Lancet Oncol 2008, 9(1):61-72.

2. Lawrence B, Gustafsson BI, Chan A, Svejda B, Kidd M, Modlin IM: The epidemiology of gastroenteropancreatic neuroendocrine tumors. Endocrinol Metab Clin North Am 2011, 40(1):1-18. vii.

3. Yao JC, Hassan M, Phan A, Dagohoy C, Leary C, Mares JE, Abdalla EK Fleming JB, Vauthey JN, Rashid A, et al: One hundred years after "carcinoid": epidemiology of and prognostic factors for neuroendocrine tumors in 35,825 cases in the United States. J Clin Oncol 2008, 26(18):3063-3072.

4. Gustafsson BI, Siddique L, Chan A, Dong M, Drozdov I, Kidd M, Modlin IM: Uncommon cancers of the small intestine, appendix and colon: an analysis of SEER 1973-2004, and current diagnosis and therapy. Int J Oncol 2008, 33(6):1121-1131.

5. Schimmack S, Svejda B, Lawrence B, Kidd M, Modlin IM: The diversity and commonalities of gastroenteropancreatic neuroendocrine tumors. Langenbecks Arch Surg 2011, 396(3):273-298.

6. Taupenot L, Harper KL, O'Connor DT: The chromogranin-secretogranin family. N Engl J Med 2003, 348(12):1134-1149.

7. Bauer MC, O'Connell DJ, Maj M, Wagner L, Cahill DJ, Linse S: Identification of a high-affinity network of secretagogin-binding proteins involved in vesicle secretion. Mol Biosyst 2011, 7(7):2196-2204. doi: 2110.1039/ c2190mb00349b. Epub 02011 Apr 00328

8. Park JJ, Gondre-Lewis MC, Eiden LE, Loh YP: A distinct trans-Golgi network subcompartment for sorting of synaptic and granule proteins in neurons and neuroendocrine cells. J Cell Sci 2011, 124(Pt 5):735-744. doi: 710.1242/ jcs. 076372 .

9. Jakobsen AM, Andersson P, Saglik G, Andersson E, Kolby L, Erickson JD, Forssell-Aronsson E, Wangberg B, AhIman H, Nilsson O: Differential expression of vesicular monoamine transporter (VMAT) 1 and 2 in gastrointestinal endocrine tumours. J Pathol 2001, 195(4):463-472.

10. Drozdov I, Svejda B, Gustafsson B, Mane S, Pfragner R, Kidd M, Modlin I: Gene Network Inference and Biochemical Assessment delineates GPCRPathways and CREB Targets in Small Intestinal Neuroendocrine Neoplasia. Plos One 2011, 6(8):e22457.

11. Christofi FL, Kim M, Wunderlich JE, Xue J, Suntres Z, Cardounel A, Javed NH, Yu $J \mathrm{~J}$, Grants I, Cooke HJ: Endogenous adenosine differentially modulates 5-hydroxytryptamine release from a human enterochromaffin cell model. Gastroenterology 2004, 127(1):188-202.

12. Bodei L, Kidd M, Modlin I, Paganelli G: Nuclear Medicine in the Diagnosis and Therapy of Neuroendocrine Tumors. In Nuclear Oncology. Edited by Akotlun C, Goldsmith S: Wolters Kluwer Health; 2014. in press.

13. Virgolini I, Ambrosini V, Bomanji JB, Baum RP, Fanti S, Gabriel M, Papathanasiou ND, Pepe G, Oyen W, De Cristoforo C, et al: Procedure guidelines for PET/CT tumour imaging with 68Ga-DOTA-conjugated peptides: 68Ga-DOTA-TOC, 68Ga-DOTA-NOC, 68Ga-DOTA-TATE. Eur J Nucl Med Mol Imaging 2010, 37(10):2004-2010

14. Zikusoka MN, Kidd M, Eick G, Latich I, Modlin IM: The molecular genetics of gastroenteropancreatic neuroendocrine tumors. Cancer 2005, 104(11):2292-2309.

15. Zhao J, de Krijger RR, Meier D, Speel EJ, Saremaslani P, Muletta-Feurer S, Matter C, Roth J, Heitz PU, Komminoth P: Genomic alterations in welldifferentiated gastrointestinal and bronchial neuroendocrine tumors (carcinoids): marked differences indicating diversity in molecular pathogenesis. Am J Pathol 2000, 157(5):1431-1438.

16. Kulke MH, Freed E, Chiang DY, Philips J, Zahrieh D, Glickman JN, Shivdasani RA: High-resolution analysis of genetic alterations in small bowel carcinoid tumors reveals areas of recurrent amplification and loss. Genes Chromosomes Cancer 2008, 47(7):591-603. doi: 510.1002/gcc.20561.

17. Kytola S, Hoog A, Nord B, Cedermark B, Frisk T, Larsson C, Kjellman M: Comparative genomic hybridization identifies loss of 18q22-qter as an early and specific event in tumorigenesis of midgut carcinoids. Am J Pathol 2001, 158(5):1803-1808.

18. Lollgen RM, Hessman O, Szabo E, Westin G, Akerstrom G: Chromosome 18 deletions are common events in classical midgut carcinoid tumors. Int $J$ Cancer 2001, 92(6):812-815.

19. Banck MS, Kanwar R, Kulkarni AA, Boora GK, Metge F, Kipp BR, Zhang L, Thorland EC, Minn KT, Tentu R, et al: The genomic landscape of small intestine neuroendocrine tumors. J Clin Invest 2013, 15:67963.

20. Kidd M, Modlin IM, Mane SM, Camp RL, Eick G, Latich I: The role of genetic markers-NAP1L1, MAGE-D2, and MTA1-in defining small-intestinal carcinoid neoplasia. Ann Surg Oncol 2006, 13(2):253-262. Epub 2006 Jan 2020.

21. Leja J, Essaghir A, Essand M, Wester K, Oberg K, Totterman TH, Lloyd R, Vasmatzis G, Demoulin JB, Giandomenico V: Mod Pathol 2009, 22(2):261-272. Epub 2008 Oct 2024

22. Edfeldt K, Bjorklund P, Akerstrom G, Westin G, Hellman P, Stalberg P: Different gene expression profiles in metastasizing midgut carcinoid tumors. Endocr Relat Cancer 2011, 18(4):479-489. Print 2011 Aug.

23. Posorski N, Kaemmerer D, Ernst G, Grabowski P, Hoersch D, Hommann M, von Eggeling F: Localization of sporadic neuroendocrine tumors by gene expression analysis of their metastases. Clin Exp Metastasis 2011, 28(7):637-647. doi: 610.1007/s10585-10011-19397-10585.

Epub 12011 Jun 10517

24. van 'tVeer $L$, Dai $H$, van de Vijver MJ, He YD, Hart AA, Mao M, Peterse $H L$, van der Kooy K, Marton MJ, Witteveen AT, et al: Gene expression profiling predicts clinical outcome of breast cancer. Nature 2002. 415(6871):530-536

25. Huang E, Cheng SH, Dressman H, Pittman J, Tsou MH, Horng CF, Bild A, Iversen ES, Liao M, Chen CM, et al: Gene expression predictors of breast cancer outcomes. Lancet 2003, 361(9369):1590-1596.

26. Hess KR, Anderson K, Symmans WF, Valero V, Ibrahim N, Mejia JA, Booser D, Theriault RL, Buzdar AU, Dempsey PJ, et al: Pharmacogenomic predictor of sensitivity to preoperative chemotherapy with paclitaxel and fluorouracil, doxorubicin, and cyclophosphamide in breast cancer. J Clin Oncol 2006, 24(26):4236-4244.

27. Cheng SH, Horng CF, West M, Huang E, Pittman J, Tsou MH, Dressman H, Chen CM, Tsai SY, Jian JJ, et al: Genomic prediction of locoregional recurrence after mastectomy in breast cancer. $J$ Clin Oncol 2006 24(28):4594-4602.

28. Helland A, Johnsen H, Froyland C, Landmark HB, Saetersdal AB, Holmen MM, Gjertsen T, Nesland JM, Ottestad W, Jeffrey SS, et al: Radiation-induced effects on gene expression: an in vivo study on breast cancer. Radiother Oncol 2006, 80(2):230-235.

29. Zander T, Hofmann A, Staratschek-Jox A, Classen S, Debey-Pascher S, Maisel D, Ansen S, Hahn M, Beyer M, Thomas RK, et al: Blood-based gene expression signatures in non-small cell lung cancer. Clin Cancer Res 2011, 17(10):3360-3367.

30. Yates DR, Roupret M, Drouin SJ, Comperat E, Ricci S, Lacave R, Sebe P, Cancel-Tassin G, Bitker MO, Cussenot O: Quantitative RT-PCR analysis of PSA and prostate-specific membrane antigen mRNA to detect circulating tumor cells improves recurrence-free survival nomogram prediction after radical prostatectomy. Prostate 2012, 6(10):22488.

31. Mead R, Duku M, Bhandari P, Cree IA: Circulating tumour markers can define patients with normal colons, benign polyps, and cancers. Br J Cancer 2011, 105(2):239-245. doi: 210.1038/bjc.2011.1230. Epub 2011 Jun 1028. 
32. Della Gatta G, Palomero T, Perez-Garcia A, Ambesi-Impiombato A, Bansal M, Carpenter ZW, De Keersmaecker K, Sole X, Xu L, Paietta E, et al: Reverse engineering of TLX oncogenic transcriptional networks identifies RUNX as tumor suppressor in T-ALL Nat Med 2012, 18(3):436-440. doi:410.1038/ $\mathrm{nm} .2610$.

33. Schreiber SL, Shamji AF, Clemons PA, Hon C, Koehler AN, Munoz B, Palmer M, Stern AM, Wagner BK, Powers S, et al: Towards patient-based cancer therapeutics. Nat Biotechnol 2010, 28(9):904-906.

34. Drozdov I, Bornschein J, Wex T, Valeyev NV, Tsoka S, Malfertheiner P: Functional and topological properties in hepatocellular carcinoma transcriptome. PLoS One 2012, 7(4):e35510. Epub 32012 Apr 35523.

35. Drozdov I, Ouzounis CA, Shah AM, Tsoka S: Functional Genomics Assistant (FUGA): a toolbox for the analysis of complex biological networks. BMC Res Notes 2011, 4(1):462.

36. Drozdov I, Tsoka S, Ouzounis CA, Shah AM: Genome-wide expression patterns in physiological cardiac hypertrophy. BMC Genomics 2010, 11:557.

37. Shepherd R, Forbes SA, Beare D, Bamford S, Cole CG, Ward S, Bindal N, Gunasekaran P, Jia M, Kok CY, et al: Data mining using the Catalogue of Somatic Mutations in Cancer BioMart. Database (Oxford) 2011, 2011: bar018. (doi):10.1093/database/bar1018. Print 2011.

38. Habib AM, Richards P, Cairns LS, Rogers GJ, Bannon CA, Parker HE, Morley TC, Yeo GS, Reimann F, Gribble FM: Overlap of endocrine hormone expression in the mouse intestine revealed by transcriptional profiling and flow cytometry. Endocrinology 2012, 153(7):3054-3065 doi: 3010.1210/ en.2011-2170. Epub 2012 Jun 3058.

39. Baysal BE: Mitochondrial complex II and genomic imprinting in inheritance of paraganglioma tumors. Biochim Biophys Acta 2013, 1827 (5):573-577. doi: 510.1016/j.bbabio.2012.1012.1005. Epub 2013 Jan 1012.

40. Alberich-Jorda M, Wouters B, Balastik M, Shapiro-Koss C, Zhang H, Di Ruscio A, Radomska HS, Ebralidze AK, Amabile G, Ye M, et al: C/EBPgamma deregulation results in differentiation arrest in acute myeloid leukemia. J Clin Invest 2012, 122(12):4490-4504. doi: 4410.1172/JCl65102. Epub 62012 Nov 65119.

41. Comprehensive molecular characterization of human colon and rectal cancer. Nature 2012, 487(7407):330-337. doi: 310.1038/nature11252.

42. Huegel J, Sgariglia F, Enomoto-Iwamoto M, Koyama E, Dormans JP, Pacifici M: Heparan sulfate in skeletal development, growth, and pathology: the case of hereditary multiple exostoses. Dev Dyn 2013, 242(9):1021-1032. doi: 1010.1002/dvdy.24010. Epub 22013 Jul 24029.

43. Merkel AL, Meggers E, Ocker M: PIM1 kinase as a target for cancer therapy. Expert Opin Investig Drugs 2012, 21(4):425-436. doi: 410.1517/ 13543784.13542012.13668527. Epub 13542012 Mar 13543784.

44. Mardis ER, Wilson RK: Cancer genome sequencing: a review. Human molecular genetics 2009, 18(R2):R163-R168.

45. Makridis C, Theodorsson E, Akerstrom G, Oberg K, Knutson L: Increased intestinal non-substance $P$ tachykinin concentrations in malignant midgut carcinoid disease. J Gastroenterol Hepatol 1999, 14(5):500-507.

46. Calhoun K, Toth-Fejel S, Cheek J, Pommier R: Serum peptide profiles in patients with carcinoid tumors. Am J Surg 2003, 186(1):28-31.

47. La Rosa S, Franzi F, Albarello L, Schmitt A, Bernasconi B, Tibiletti MG, Finzi G, Placidi C, Perren A, Capella C: Serotonin-producing enterochromaffin cell tumors of the pancreas: clinicopathologic study of 15 cases and comparison with intestinal enterochromaffin cell tumors. Pancreas 2011, 40(6):883-895. doi: 810.1097/ MPA.1090b1013e31822041a31822049.

48. Cui T, Hurtig M, Elgue G, Li SC, Veronesi G, Essaghir A, Demoulin JB, Pelosi G, Alimohammadi M, Oberg K, et al: Paraneoplastic antigen Ma2 autoantibodies as specific blood biomarkers for detection of early recurrence of small intestine neuroendocrine tumors. PLOS One 2010, 5(12):e16010.

49. Arvidsson $Y$, Andersson E, Bergstrom A, Andersson MK, Altiparmak G, Illerskog AC, Ahlman H, Lamazhapova D, Nilsson O: Amyloid precursorlike protein 1 is differentially upregulated in neuroendocrine tumours of the gastrointestinal tract. Endocr Relat Cancer 2008, 15 (2):569-581. doi:510.1677/ERC-1607-0145. Epub 2008 Apr 1622.

50. Gagnon J, Mayne J, Mbikay M, Woulfe J, Chretien M: Expression of PCSK1 (PC1/3), PCSK2 (PC2) and PCSK3 (furin) in mouse small intestine. Regul Pept 2009, 152(1-3):54-60. doi:10.1016/j.regpep.2008.1007.1006. Epub 2008 Jul 1022.

51. Thimmapaya R, Neelands T, Niforatos W, Davis-Taber RA, Choi W, Putman CB, Kroeger PE, Packer J, Gopalakrishnan M, Faltynek CR, et al: Distribution and functional characterization of human Nav1.3 splice variants. Eur J Neurosci 2005, 22(1):1-9.

52. Kidd M, Modlin IM, Gustafsson BI, Drozdov I, Hauso O, Pfragner R: Luminal regulation of normal and neoplastic human EC cell serotonin release is mediated by bile salts, amines, tastants, and olfactants. Am J Physiol Gastrointest Liver Physiol 2008, 295(2):G260-G272

53. Hains BC, Klein JP, Saab CY, Craner MJ, Black JA, Waxman SG: Upregulation of sodium channel Nav1.3 and functional involvement in neuronal hyperexcitability associated with central neuropathic pain after spinal cord injury. J Neurosci 2003, 23(26):8881-8892.

54. Jandrig B, Seitz S, Hinzmann B, Arnold W, Micheel B, Koelble K, Siebert R, Schwartz A, Ruecker K, Schlag PM, et al: ST18 is a breast cancer tumor suppressor gene at human chromosome 8 q11.2. Oncogene 2004, 23(57):9295-9302.

55. Yang J, Siqueira MF, Behl Y, Alikhani M, Graves DT: The transcription factor ST18 regulates proapoptotic and proinflammatory gene expression in fibroblasts. Faseb J 2008, 22(11):3956-3967. doi:3910.1096/fj.3908-111013. Epub 112008 Aug 111011.

56. Kameyama T, Matsushita F, Kadokawa Y, Marunouchi T: Myt/NZF family transcription factors regulate neuronal differentiation of $\mathrm{P} 19$ cells. Neurosci Lett 2011, 497(2):74-79. doi:10.1016/..neulet.2011.1004.1033. Epub 2011 Apr 1022.

57. Wang S, Zhang J, Zhao A, Hipkens S, Magnuson MA, Gu G: Loss of Myt1 function partially compromises endocrine islet cell differentiation and pancreatic physiological function in the mouse. Mech Dev 2007, 124(11-12):898-910. Epub 2007 Sep 2004

58. Khazaei MR, Halfter H, Karimzadeh F, Koo JH, Margolis FL, Young P: Bex1 is involved in the regeneration of axons after injury. J Neurochem 2010, 115(4):910-920. doi:910.1111/j.1471-4159.2010.06960.x. Epub 02010 Sep 06928.

59. Hofsli E, Wheeler TE, Langaas M, Laegreid A, Thommesen L: Identification of novel neuroendocrine-specific tumour genes. $\mathrm{Br} J$ Cancer 2008, 99(8):1330-1339. doi:1310.1038/sj.bjc.6604565. Epub 6602008 Sep 6604530.

60. Ruau D, Ensenat-Waser R, Dinger TC, Vallabhapurapu DS, Rolletschek A Hacker C, Hieronymus T, Wobus AM, Muller AM, Zenke M: Pluripotency associated genes are reactivated by chromatin-modifying agents in neurosphere cells. Stem Cells 2008, 26(4):920-926. doi:910.1634/stemcells.2007-0649. Epub 2008 Jan 1617.

61. Borczuk AC, Gorenstein L, Walter KL, Assaad AA, Wang L, Powell CA: Nonsmall-cell lung cancer molecular signatures recapitulate lung developmental pathways. Am J Pathol 2003, 163(5):1949-1960.

62. Kalari $S$, Jung M, Kernstine KH, Takahashi T, Pfeifer GP: The DNA methylation landscape of small cell lung cancer suggests a differentiation defect of neuroendocrine cells. Oncogene 2012, 20(10):362.

63. Rosenbaum JN, Duggan A, Garcia-Anoveros J: Insm1 promotes the transition of olfactory progenitors from apical and proliferative to basal, terminally dividing and neuronogenic. Neural Dev 2011, 6:6. (doi):10.1186/1749-8104-1186-1186.

64. Horb LD, Jarkji ZH, Horb ME: Xenopus insm1 is essential for gastrointestinal and pancreatic endocrine cell development. Dev Dyn 2009, 238(10):2505-2510. doi:2510.1002/dvdy.22071.

65. Zhang T, Liu WD, Saunee NA, Breslin MB, Lan MS: Zinc finger transcription factor INSM1 interrupts cyclin D1 and CDK4 binding and induces cell cycle arrest. J Biol Chem 2009, 284(9):5574-5581. doi:5510.1074/jbc.M808843200. Epub 808842009 Jan 808843205

66. Zhang T, Saunee NA, Breslin MB, Song K, Lan MS: Functional role of an islet transcription factor, INSM1/IA-1, on pancreatic acinar cell trans-differentiation. J Cell Physiol 2012, 227(6):2470-2479. doi:2410.1002/ jcp.22982.

67. Desai S, Loomis Z, Pugh-Bernard A, Schrunk J, Doyle MJ, Minic A, McCoy E, Sussel L: Nkx2.2 regulates cell fate choice in the enteroendocrine cell lineages of the intestine. Dev Biol 2008, 313(1):58-66. Epub 2007 Oct 2003.

68. Kordowich S, Collombat P, Mansouri A, Serup P: Arx and Nkx2.2 compound deficiency redirects pancreatic alpha- and beta-cell differentiation to a somatostatin/ghrelin co-expressing cell lineage. BMC Dev Biol 2011, 11:52. doi:10.1186/1471-1213X-1111-1152.

69. Papizan JB, Singer RA, Tschen SI, Dhawan S, Friel JM, Hipkens SB, Magnuson MA, Bhushan A, Sussel L: Nkx2.2 repressor complex regulates islet betacell specification and prevents beta-to-alpha-cell reprogramming. Genes Dev 2011, 25(21):2291-2305. doi: 2210.1101/gad.173039.173111. 
70. Liu W, Enwright JF 3rd, Hyun W, Day RN, Schaufele F: CCAAT/enhancer binding protein alpha uses distinct domains to prolong pituitary cells in the growth 1 and DNA synthesis phases of the cell cycle. BMC Cell Biol 2002, 3:6.

71. Keeshan K, Santilli G, Corradini F, Perrotti D, Calabretta B: Transcription activation function of C/EBPalpha is required for induction of granulocytic differentiation. Blood 2003, 102(4):1267-1275. Epub 2003 Apr 1217

72. von Wichert $G$, Jehle PM, Hoeflich A, Koschnick S, Dralle H, Wolf E, Wiedenmann B, Boehm BO, Adler G, Seufferlein T: Insulin-like growth factor-l is an autocrine regulator of chromogranin A secretion and growth in human neuroendocrine tumor cells. Cancer Res 2000, 60(16):4573-4581.

73. Zhou Y, Wang S, Yue BG, Gobl A, Oberg K: Effects of interferon alpha on the expression of p21cip1/waf1 and cell cycle distribution in carcinoid tumors. Cancer Invest 2002, 20(3):348-356.

74. Hoekstra AS, Bayley JP: The role of complex II in disease. Biochim Biophys Acta 2013, 1827(5):543-551. doi:510.1016/j.bbabio.2012.1011.1005. Epub 2012 Nov 1020

75. Perren A, Barghorn A, Schmid S, Saremaslani P, Roth J, Heitz PU, Komminoth P: Absence of somatic SDHD mutations in sporadic neuroendocrine tumors and detection of two germline variants in paraganglioma patients. Oncogene 2002, 21(49):7605-7608.

76. Katona TM, Jones TD, Wang M, Abdul-Karim FW, Cummings OW, Cheng L: Molecular evidence for independent origin of multifocal neuroendocrine tumors of the enteropancreatic axis. Cancer Res 2006, 66(9):4936-4942.

77. Drozdov I, Kidd M, Nadler B, Camp RL, Mane SM, Hauso O, Gustafsson BI, Modlin IM: Predicting neuroendocrine tumor (carcinoid) neoplasia using gene expression profiling and supervised machine learning. Cancer 2009, 115(8):1638-1650.

78. Modlin IM, Gustafsson BI, Drozdov I, Nadler B, Pfragner R, Kidd M: Principal component analysis, hierarchical clustering, and decision tree assessment of plasma mRNA and hormone levels as an early detection strategy for small intestinal neuroendocrine (carcinoid) tumors. Ann Surg Oncol 2009, 16(2):487-498.

79. Modlin I, Drozdov I, Kidd M: The Identification of gut neuroendocrine tumor disease by multiple synchronous transcript analysis in blood. Plos One 2013, 8(5):e63364.

80. McClintick JN, Edenberg HJ: Effects of filtering by Present call on analysis of microarray experiments. BMC Bioinformatics 2006, 7:49.

81. Irizarry RA, Bolstad BM, Collin F, Cope LM, Hobbs B, Speed TP: Summaries of Affymetrix GeneChip probe level data. Nucleic Acids Res 2003, 31(4):e15.

82. Kauffmann A, Gentleman R: Huber W: arrayQualityMetrics-a bioconductor package for quality assessment of microarray data. Bioinformatics 2009, 25(3):415-416.

83. Maglott D, Ostell J, Pruitt KD, Tatusova T: Entrez Gene: gene-centered information at NCBI. Nucleic Acids Res 2011, 39(Database issue):D52-D57.

84. Boulesteix AL, Slawski M: Stability and aggregation of ranked gene lists. Briefings in bioinformatics 2009, 10(5):556-568.

85. Alexa A, Rahnenfuhrer J, Lengauer T: Improved scoring of functional groups from gene expression data by decorrelating GO graph structure. Bioinformatics 2006, 22(13):1600-1607.

86. Croft D, O'Kelly G, Wu G, Haw R, Gillespie M, Matthews L, Caudy M, Garapati P, Gopinath G, Jassal B, et al: Reactome: a database of reactions, pathways and biological processes. Nucleic acids research 2011, 39(Database issue):D691-D697.

87. Bauer S, Robinson PN, Gagneur J: Model-based gene set analysis for Bioconductor. Bioinformatics 2011, 27(13):1882-1883.

88. Stark C, Breitkreutz BJ, Reguly T, Boucher L, Breitkreutz A, Tyers M: BioGRID: a general repository for interaction datasets. Nucleic Acids Res 2006, 34(Database issue):D535-D539.
89. Clauset $A$, Newman MEJ, Moore C: Finding community structure in very large networks. Phys Rev E 2004, 70(6):066111.

90. Kidd M, Eick G, Shapiro MD, Camp RL, Mane SM, Modlin IM: Microsatellite instability and gene mutations in transforming growth factor-beta type II receptor are absent in small bowel carcinoid tumors. Cancer 2005, 103(2):229-236.

91. Kidd M, Nadler B, Mane S, Eick G, Malfertheiner M, Champaneria M, Pfragner R, Modlin I: GeneChip, geNorm, and gastrointestinal tumors: novel reference genes for real-time PCR. Physiol Genomics 2007, 30(3):363-370.

92. Dalman MR, Deeter A, Nimishakavi G, Duan ZH: Fold change and p-value cutoffs significantly alter microarray interpretations. BMC Bioinformatics 2012, 13(Suppl 2):S11.

doi:10.1186/1471-2164-15-595

Cite this article as: Kidd et al:: Gene network-based analysis identifies two potential subtypes of small intestinal neuroendocrine tumors. BMC Genomics 2014 15:595.

\section{Submit your next manuscript to BioMed Central and take full advantage of:}

- Convenient online submission

- Thorough peer review

- No space constraints or color figure charges

- Immediate publication on acceptance

- Inclusion in PubMed, CAS, Scopus and Google Scholar

- Research which is freely available for redistribution

Submit your manuscript at www.biomedcentral.com/submit
C Biomed Central 